\title{
9. Mobilization and participation: a win-win game?
}

\author{
VERA SCHATTAN P. COELHO, ALEXANDRE \\ FERRAZ, FABIOLA FANTI AND MEIRE RIBEIRO ${ }^{1}$
}

Governments and social organizations are finding it increasingly difficult to sustain the involvement of citizens in the decision-making processes that surround the development of public policies. There are several risks that are now recognized as potentially harmful to the project of participatory governance. Among them are the absence of lively social forces engaging in participatory processes, and their 'capture' by more organized groups (Avritzer and Navarro, 2003; Coelho and Nobre, 2004; Ansell and Gash, 2008). Two recommendations have been widely suggested to deal with these risks. The first is to redesign participatory bodies (Fung, 2004); the second is to mobilize social actors (Gaventa, 2006a; Mohanty, 2007; Cornwall, 2007). In this chapter, we will argue that these recommendations often lead to a zero-sum game, since mobilization without design increases the risk that more organized groups will 'capture' the processes, while redesign without social mobilization can easily lead to the adoption of formal procedures that contribute to the inhibition of a more spontaneous and vibrant participation. As an alternative, we will suggest that the conjunction of mobilization and design may increase the chances of success of the participatory governance project.

In order to explore the possibilities and limits of mobilization and design in fostering citizen involvement in the decision-making processes of public policies, we have researched the dynamics of conselhos locais da saúde (CLS - local health councils) organized in peripheral areas of the city of São Paulo, Brazil. The aim was to understand the relationship between the forms of mobilization that emanate from the citizenry, the architecture of these governance structures and the public-health debates taking place in these areas.

CLSs were introduced by the 1988 Brazilian Constitution, which established the formal transition to democracy after more than twenty years of military regime. The so-called 'Citizen Constitution' defined health councils as mechanisms responsible for bringing civil society organizations (CSOs), service providers and public officials together 
in health governance. Today, there is a national health council as well as state, municipal and, in large cities, local health councils. Health councils operate in all twenty-six states and nearly all 5,561 municipalities, addressing core issues of priority-setting and accountability. Our research focused on six CLSs located in poor regions of the city of São Paulo, each with a different history of social mobilization. We compared council dynamics in terms of inclusiveness, connections, participation and the debates held. These dimensions are closely related to the three axes which, Dryzek (2000) argues, are essential to democratization: expansion of the number of people effectively included in collective decisions; broadening of the issues and areas of life under democratic control; and extension of the effective participation of autonomous and competent actors.

In the next section, we situate the Brazilian health councils in the international debate about deepening democracy and participatory governance. We then present our research methodology. The fourth section introduces the municipal areas under study. Next, we describe the composition, connections and dynamics of the six CLSs, and present the debates that took place in them. We also discuss the relationship between the local history of social mobilization and the councils' performance. Finally, methodological and analytical aspects of the research are discussed.

\section{The deepening democracy debate}

It has increasingly been argued that it is necessary to go beyond implementation of democracy's formal and structural dimensions to release its potential for transformation. In parallel with regular elections, free political parties and freedom of speech and association, the implementation of mechanisms capable of promoting greater citizen involvement in public decisions, greater transparency and a greater and more horizontal flow of information should be encouraged. Throughout the 1980 s and 1990s, different theoretical perspectives discussed 'deeper' or improved forms of democracy, and several experiences based on the ideals of participation, deliberation and decentralization were implemented and reported all over the world (Habermas et al., 1998; Fung and Wright, 2003; Dryzek, 2000; Gastil and Levine, 2005; Gaventa, 2006a).

However, many of these experiences exposed the limits and risks present in the processes of 'deepening' democracy. The risks have been set out by a number of authors who are sceptical about the effects of participation. Their warnings echo the concerns previously raised by such authors as Weber (1946) and Schumpeter (1976), who pointed 
to the possibility of perverse effects. These include the populism and opportunism that permeate leaders who are connected to the masses without the intermediary of parties; fears regarding asymmetries in the ability of different people to mobilize and participate; and warnings that narrow interests will be able to organize more easily, thereby rendering unviable those policies that are aimed at a broader, yet less organized, public. Robinson (2007), in summarizing the findings of comparative research on decentralization and participation, points to five major limitations: a) lack of political commitment or leadership on the part of local elites with regard to the new participatory spaces; b) lack of political mobilization of the poor; c) inadequate financial resources to guarantee the sustainability of participatory experiences; d) lack of institutionalization of participatory spaces and mechanisms; and e) lack of technical and managerial capacity, as well as inequality of information among participants.

On the other hand, a number of authors have shown that, given certain design conditions, the organization of civil society and the involvement of public managers, there are redistributive gains and an increase in participation in the political process by traditionally marginalized groups (Abers, 2001; Wampler and Avritzer, 2004; Coelho and Nobre, 2004). These authors also demonstrate that deliberative processes contribute towards changing the positions and opinions of participants, narrowing the gap between people's opinions on contentious issues (Abelson and Gauvin, 2006).

Recent work that departed from this more optimistic perspective ended up by pointing out that important questions on the democratic potential of participatory processes remain open (Coelho, 2006; Melo and Baiocchi, 2006; Dagnino and Tatagiba, 2007; Bebbington et al., 2008). Given the informality that is a feature of participation in deliberative processes, how can we check whether traditionally marginalized groups with no party-political connections or relationships with public managers have been included in the process or have accessed its distributive benefits? Furthermore, how can we tell if there is greater accountability in the way that the policies are being provided? Are the public policies that are being generated from information provided by civil society representatives innovative?

In sum, these works call attention to the fact that there are currently no specifications about the quality either of the processes (inclusion, involvement and transparency) or of the outcomes that are being attributed to participation (innovation, distribution). What degree of inclusion, or what amount of innovation, needs to be proposed before 